\title{
Quantifying Suspended Sediment using Acoustic Doppler Current Profiler in Tidung Island Seawaters
}

\author{
Henry Munandar Manik ${ }^{1 *}$ and Randi Firdaus ${ }^{2}$ \\ ${ }^{1}$ Division of Ocean Acoustics and Instrumentation, Department of Marine Science and Technology, Faculty \\ of Fisheries and Marine Sciences, Bogor Agricultural University (IPB University), Kampus IPB Dramaga, \\ Bogor 16680 Indonesia \\ ${ }^{2}$ Marine Technology Study Program, IPB University Graduate School, Kampus IPB Dramaga Bogor Indonesia, \\ and Meteorological, Climatological, and Geophysical Agency, Indonesia
}

\begin{abstract}
Tidung Island, located near Jakarta Bay, is a tourism and conservation area. It is necessary to keep these seawaters unpolluted. To calculate the level of pollution, it is necessary to know the sediment concentration. Quantifying concentration suspended sediment is important for knowledge of sediment transport. Researchers usually use water sample analysis and optical method for quantifying suspended sediment in seawater. Less accuracies of these methods are due to under sample of seawater and the existence of biological fouling. One promising method to measure concentration of suspended sediment is using Acoustic Doppler Current Profiler (ADCP). ADCP is usually used by oceanographer and hydrographer to measure ocean current. In this research, ADCP with $300 \mathrm{kHz}$ operating frequency was used effectively to measure suspended sediment concentration (SSC) and ocean current simultaneously. The echo intensity received from suspended sediment was computed using sonar equations to quantify SSC. The empirical equation between echo intensity and SSC was found. The SSC value obtained by ADCP was also compared with in situ measurement. The result showed that quantified SSC value obtained by ADCP was nearly equal with SSC obtained from in situ measurement with coefficient

ARTICLE INFO

Article history:

Received: 24 May 2020

Accepted: 05 October 2020

Published: 22 January 2021

DOI: https://doi.org/10.47836/pjst.29.1.21

E-mail addresses:

henrymanik@apps.ipb.ac.id (Henry Munandar Manik)

randi_firdaus@apps.ipb.ac.id (Randi Firdaus)

* Corresponding author

correlation of 0.98 . The high concentration ranged from $55 \mathrm{mg} / \mathrm{L}$ to $80 \mathrm{mg} / \mathrm{L}$ at the surface layer to a depth $12 \mathrm{~m}$, moderate concentration ranged from $45 \mathrm{mg} / \mathrm{L}$ to 55 $\mathrm{mg} / \mathrm{L}$ at a depth $12 \mathrm{~m}$ to $40 \mathrm{~m}$, and low concentration less than $45 \mathrm{mg} / \mathrm{L}$ at a depth greater than $40 \mathrm{~m}$. The distribution of SSC
\end{abstract}


was correlated with ocean current condition. In small currents, suspended solids will settle faster so that the concentration in the water column will decrease. Conversely, if the velocity is high, suspended solids will continue to float carried by the current in the water column so that the concentration is high.

Keywords: Acoustic Doppler Current Profiler, suspended sediment concentration, Tidung Island

\section{INTRODUCTION}

Improvement of sediment transport monitoring is a crucial for coastal management. Knowledge of sediment concentration provides a better understanding of marine environment. Degradation of marine fisheries resources can damage coastal ecosystems such as fish, coral reefs, and another marine biota. Therefore, the study to quantify sediment concentration is vital to detecting and monitoring sediment in the ocean. The decrease of photosynthesis is caused by the high concentration of suspended sediment.

Suspended sediment is one of marine pollution indicator that is very important in the aquatic environment. In coral reef ecosystems in coastal areas, the life of underwater biota is strongly influenced by the concentration of suspended sediments. But until now, the measurement of suspended sediment concentrations is still constrained by conventional methods, which cannot be measured continuously. The Acoustic Doppler Current Profiler (ADCP) device, which was originally designed to measure the profile of ocean current speed and direction, can be used to measure suspended sediment concentrations simultaneously by converting echo intensity from sediment using Sonar equation.

Determination of suspended sediment concentrations is of fundamental importance in studying sediment transport (American Public Health Association, 2012). Measurement of suspended sediment concentration can be conducted in two ways, namely by gravimetry and acoustic methods. The conventional method using the gravimetric method in the laboratory has several disadvantages, namely requiring many water samples at each point and depth of the observation station, therefore it is not possible to gather time series data. Other reason is this method takes time to conduct and thus needs more budget (Medwin \& Clay, 1997; Ainsle \& McColm, 1998; Deines, 1999; Downing, 1996; Poerbandono \& Mayerle, 2004; Ghaffari et al., 2011; Poerbandono \& Suprijo, 2013). Therefore, ADCP instruments are used as an alternative since it can produce continuous suspended sediment concentration, (SSC) data with a long-time scale and broad distribution (Manik et al., 2020).

\section{State of the Art}

The current study demonstrates the application of sonar equation to quantify echo intensity of ADCP instrument and measure the suspended sediment concentration in Tidung Island seawaters, Indonesia. ADCP is usually to measure ocean current, however in this research 
measurement of suspended sediment concentration and ocean current was simultaneously conducted.

The hydroacoustic technology utilizes sound waves for various purposes of underwater detection. The ADCP device is able to detect and quantify underwater objects accurately by emitting sound to the target then the target reflects back sound waves until they are received by acoustic devices (Holdaway et al., 1999; Gartner \& Cheng, 2001; Gruber et al., 2016). Through acoustic signals obtained, the determination of spatial and temporal suspended sediment concentrations can be better obtained when compared to conventional methods.

This research is significant to monitor the condition of marine waters in the ecosystem of Jakarta Bay from the threat of suspended sediment pollution. The objective was to quantify real time and accurate of the acoustic intensity obtained from ADCP instrument to be used in determining the suspended sediments concentration (SSC).

\section{METHODS}

The procedure for collecting field data included data collection using ADCP and water sampling. Data processing carried out the conversion of data in the form of echo intensity from ADCP to the concentration of suspended sediments. In laboratory measurements, gravimetric analysis was compared to acoustic method for suspended sediment concentrations measurements. The value of suspended sediment concentration obtained from the results of analysis in the laboratory was in absolute value, so the level of confidence was very high.

Figure 1 shows data acquisition using one ADCP moves with downward-looking sound waves. Data acquisition was done with two lines that represent the characteristics of the waters of Tidung Island. Determination of the data collection transect line is based on the location in the field, namely the water near the port and in a location far from the port.

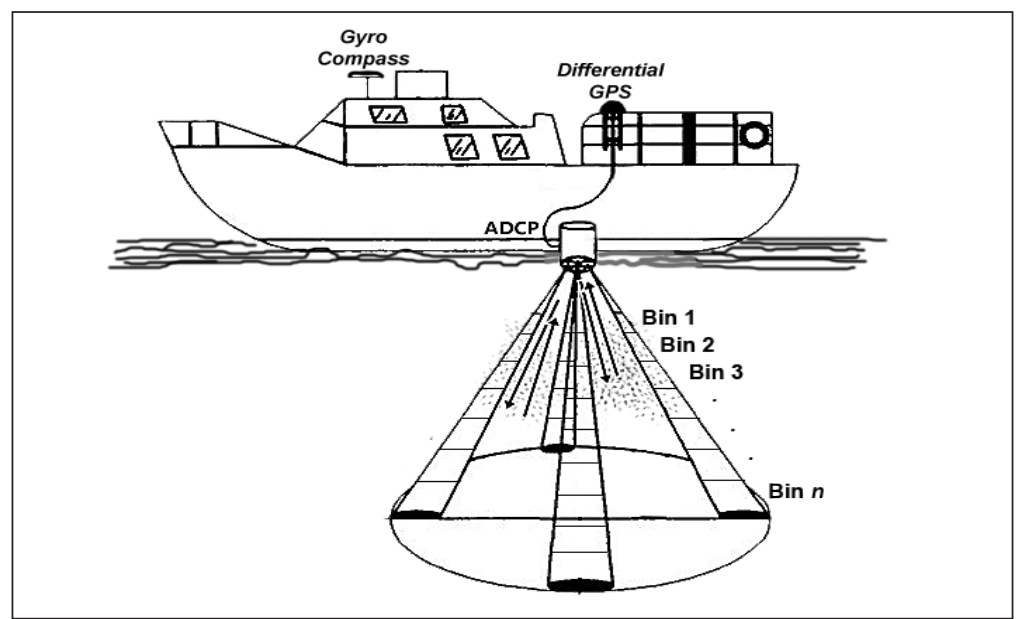

Figure 1. The method of data acquisition using the ADCP in a downward-looking method 
Water sampling was carried out during the high tide and low tide period with the aim of comparing the measurement results from the ADCP.

The ADCP instrument was installed at 0.65 meters below the sea surface, the maximum depth of detection was 50 meters, and the thickness of the bin and hose data was 1 meter and 1 second. ADCP are designed for motion is relatively slow and unaffected by ocean waves. A flux-gate compass and inclinometers can measure pitch, roll, and heading effectively.

Echo intensity was derived from ADCP calibrated with the laboratory measurement and analyzed using a linear regression. The results of the analysis produce slope and intercept values could be used in the process of converting echo intensity (EI) values to SSC using Valeport Datalog X2 software to produce spreadsheets, then plotted in MATLAB.

In this research we also used a sensor to measure turbidity value of seawater and correlated it with SSC value.

\section{Sonar Equation for ADCP}

ADCP instrument transmits the acoustic signal into water column and hits the underwater object such as suspended sediment (Simmonds \& MacLennan, 2005). The acoustic signal from suspended sediment was backscattered to the ADCP transducer. The value of acoustic backscatter was processed to quantify suspended sediment using Sonar Equation. The foundational sonar equation between $S S C$ and the relative backscatter $(R B)$ can be expressed as in decibel (dB) (Equation 1) (Gartner, 2004):

$$
S S C=10^{(A+B \cdot R B)} \text { or } 10 \log (S S C)=A+B \cdot(R B)
$$

where $A$ and $B$ are empirical parameters derived from known $S S C$ and $R B$ data pairs.

The relative backscatter is the measured acoustic backscatter corrected for transmission losses in units of dB. Acoustic waves in the water will experience sound propagation in the form of geometric attenuation and shrinkage due to the presence of suspended sediments in the water column.

Relating $R B$ and $S S C$ can be expressed as Equation 2:

$$
R B=R L+2 T L
$$

where $R L$ is the reverberation level and 2.TL is the two way transmission loss. The $R L$ is given as Equation 3:

$$
R L=S L-2 T L+T S
$$


where $S L$ is source level and TS is target strength of suspended sediment. Here TS depends on acoustic frequency, particle size and shape, and rigidity. ADCP instrument measures the $R L$ using Equation 4:

$$
R L=K_{c}\left(E I-E_{r}\right)
$$

where $K_{c}$ is the received signal strength indicator scale factor, $E I$ is the echo strength (counts), $E_{r}$ is the reference level for echo intensity (counts). $K_{c}$ can be estimated using Equation 5:

$$
K_{c}=\frac{127.3}{T+273}
$$

where $T$ is the real time temperature of the amplification circuits in ${ }^{\circ} \mathrm{C}$. Measuring Transmission Loss $(T L)$ depends on spherical spreading of the beam and absorption of sound, and is given by Equation 6:

$$
T L=10 \Psi \log (R)+\alpha R
$$

where $\Psi$ is a near field correction factor, $R$ is the slant range from transducer head to measured bin $(\mathrm{m}), \alpha$ is absorption coefficient of sea water and attenuation from suspended sediment. (Francois \& Garrison, 1982a; Francois \& Garrison, 1982b; Sassi et al., 2012). The correction factor for near field spreading loss is (Equation 7):

$$
\psi=\frac{1+1.35 Z+(2.5 Z)^{3.2}}{\left[1.35 Z+(2.5 Z)^{3.2}\right]}
$$

where $Z=R / R_{\text {critical }}$ and $R_{\text {critical }}=\pi a^{2} / \lambda ., a$ is the radius of transducer (cm) and $\lambda$ is acoustic wavelength. Sound absorption in sea water is calculated by Equation 8:

$$
\alpha_{w}=8.687 \frac{3.38 \cdot 10^{-6} \cdot f^{2}}{f_{r}}
$$

where $f$ is operating frequency $(\mathrm{Hz})$ of $\mathrm{ADCP}$ and $f_{r}$, the relaxation frequency $(\mathrm{Hz})$ depends on sea water temperature (T) as in Equation 9:

$$
f_{r}=21,9 \times 10^{\left(6-\frac{1520}{273+T}\right)}
$$


The attenuation due to absorption of sediment $\left(\alpha_{s}\right)$ is calculated in this research by Equation 10:

$$
\alpha_{s}=-\frac{1}{2} \frac{d}{d r}(W)
$$

where $W$ is water corrected backscatter.

Final equation of SSC is expressed by Equation 11:

$$
S S C=10^{A+B\left(K_{C}\left(E I-E_{r}\right)+2(10 \log (R)+\alpha R)\right)}
$$

where echo intensity $(E I)$, slant range $(R)$ and reference level $\left(E_{r}\right)$ can be measured with ADCP, while $K_{c}$ and $\alpha$ are estimated.

The data used are scattered backwater water intensity data from four beams of ADCP type RDI Workhouse $307.2 \mathrm{kHz}$ on lines 1 and 2 on the waters around Tidung Island showed in Figure 2. Line 1 is in the north of Tidung Island while line 2 is in the South of Tidung Island.

For gravimetric method, one liter of seawater was sampled and analyzed in the laboratory. A $500 \mathrm{ml}$ of sub water sample was used and then processed with vacuum-filtered with a $1.5 \mu \mathrm{m}$ particle retention. The filters were dried for 24 hours at $100{ }^{\circ} \mathrm{C}$, reweighed to measure in situ concentration of suspended sediment.

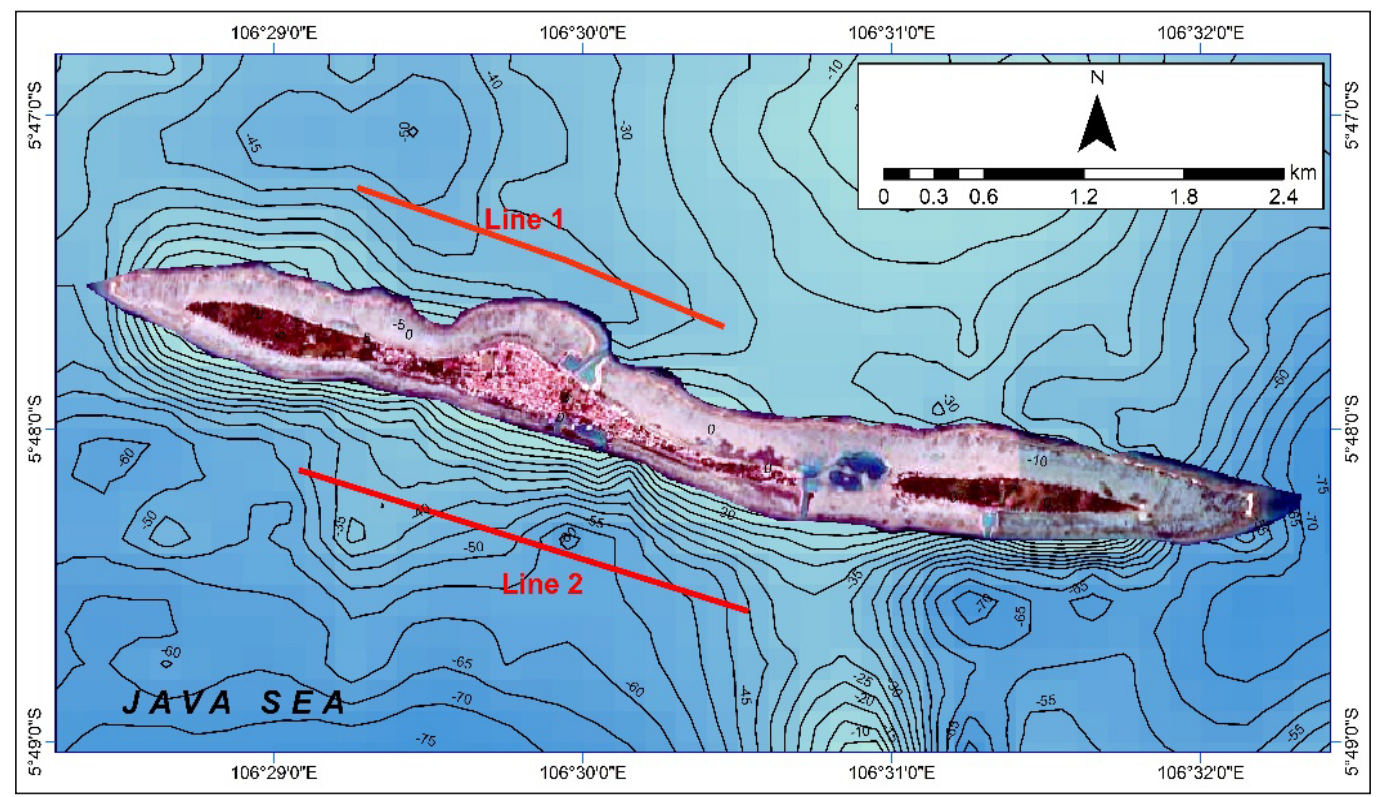

Figure 2. Analyzed track location (- Lines 1 and 2 are for collecting ADCP data). Sea water depth ranged from 5 to $60 \mathrm{~m}$ 


\section{RESULTS AND DISCUSSIONS}

Figures 3 and 4 show the linear relationship between the scattering value of each beam with other beams. Figures 3 and 4 illustrate the echo intensity detection in Count unit resulted
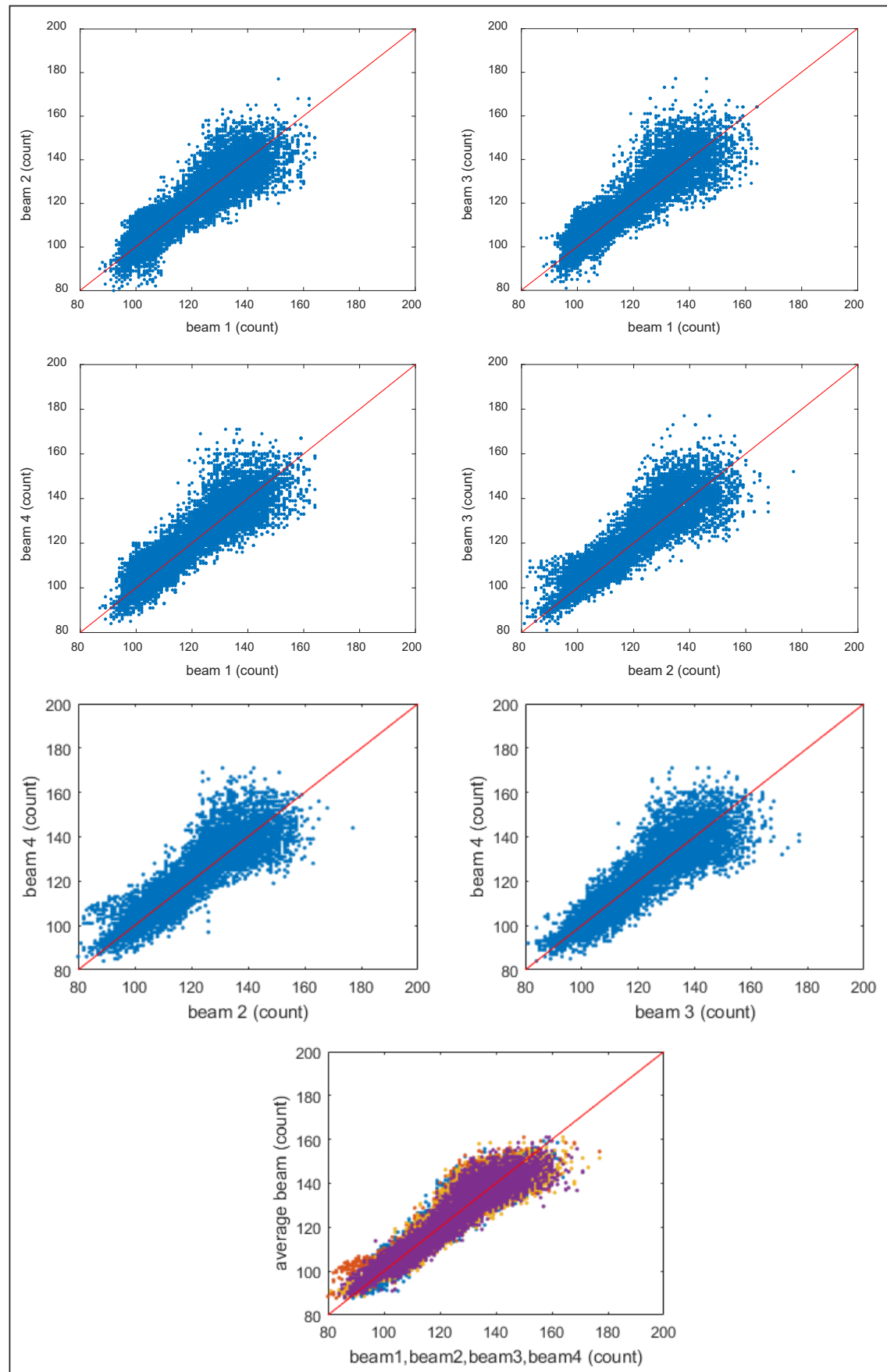

Figure 3. Comparison of backscatter values in line 1 


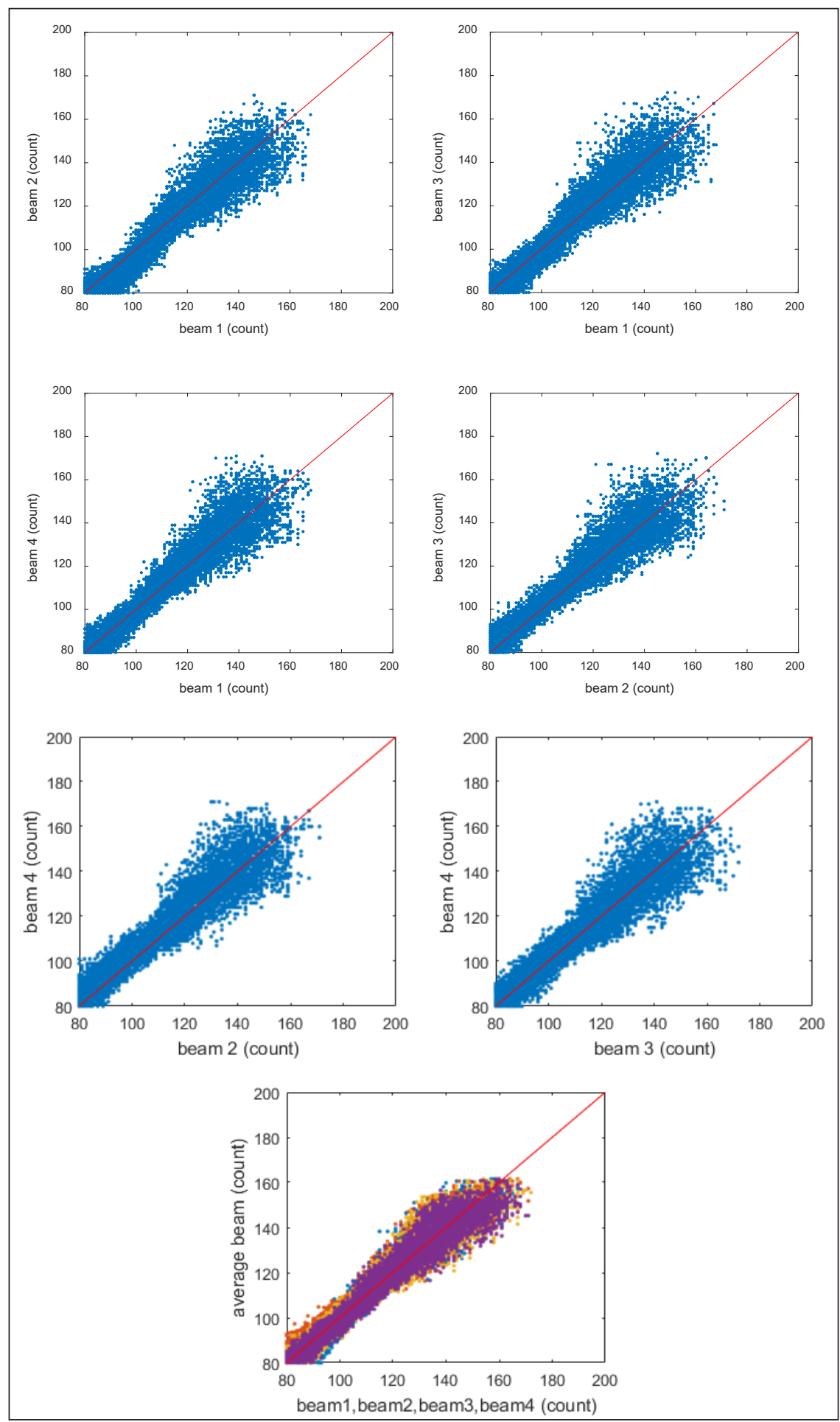

Figure 4. Comparison of backscatter values between beams in line 2 
from the four beams of ADCP and comparison this echo for each beam from the ADCP transducer. Finally, the average signal of each beam was combined to further process of echo intensity to measure suspended sediment concentration.

The screening of data was performed on ADCP data recorded in each beam. A beam to beam comparison of the echo intensity value was conducted for all four ADCP beams. Figures 3 and 4 show the scatterplot of echo intensity (blue dot colour) for each beam and for combined ADCP beam (red dot colour). Echo intensity data were recorded in beam coordinated and the data quality were retained for ensemble of each beam. The applications of the comparison ADCP beams is to provide careful application of the instrument calibration and particular attention to the measurement of echo intensity of the beam-by-beam.

Figure 5 shows the curve of echo intensity against suspended sediment calibration obtained from ADCP with a high correlation coefficient $(r)$ of 0.96 in Equation 12. Figure 6 shows the SSC estimated by ADCP compare to direct measurement of SSC using gravimetric analysis with $r=0.98$ in Equation 13. Figure 7 shows the high relationship between turbidity (NTU) and SSC (mg/L) with $r=0.91$ in Equation 14:

$$
\begin{aligned}
& 10 \log _{10}(S S C)=0.2843 E I(\mathrm{~dB})-46.66 \\
& S S C_{\text {est }}=10^{1.0607 \mathrm{RB}-2.32} \\
& S S C=1.8395 \text { Turbidity }^{0.901}
\end{aligned}
$$

The results of the conversion of counts into relative backscatter (relative $\mathrm{dB}$ ) in line 1 are presented in Figures 8 and 9. Conversions were carried out by a scale factor of 0.43

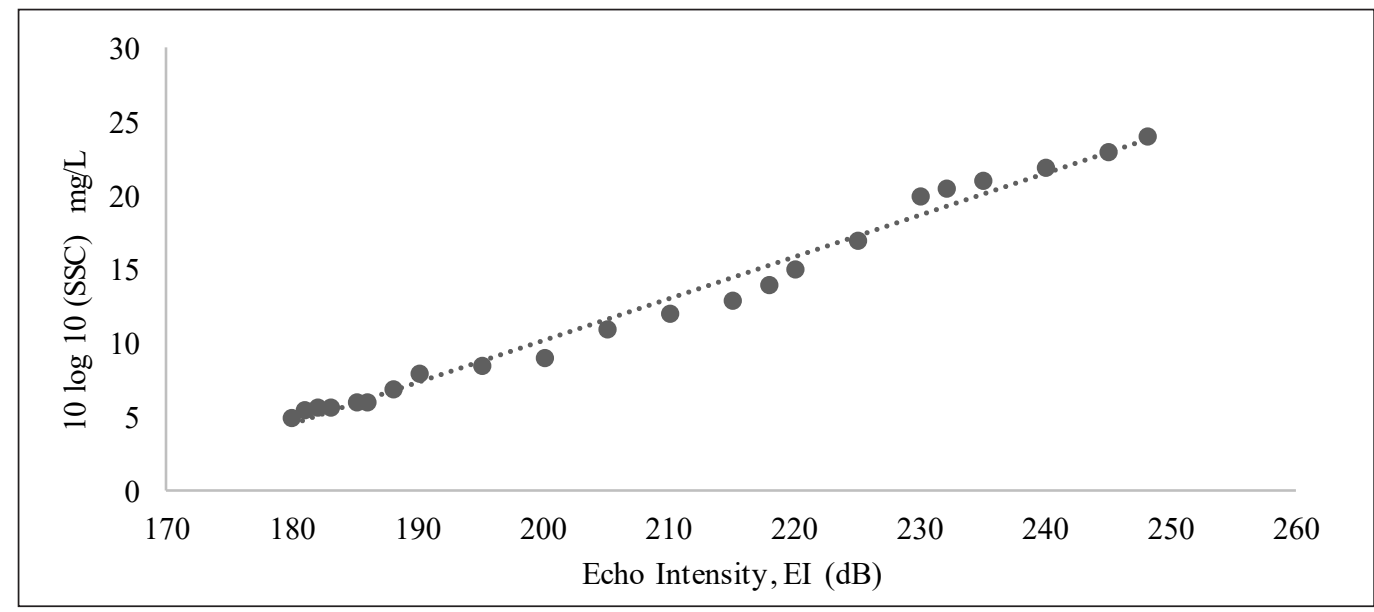

Figure 5. Echo intensity against direct sample of suspended sediment concentration (SSC) 


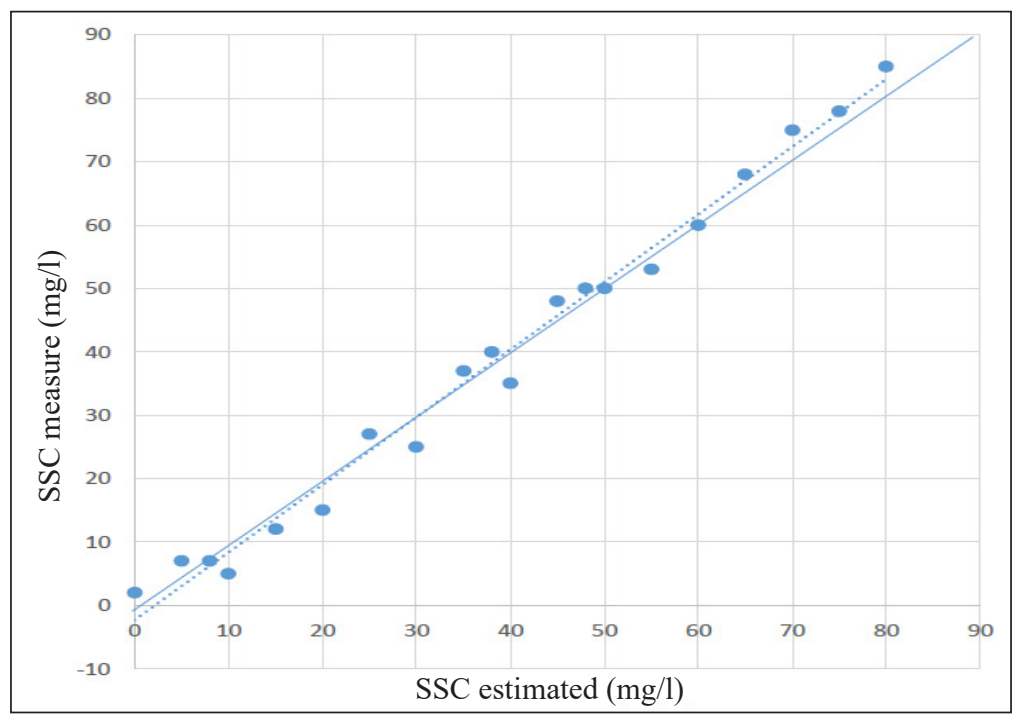

Figure 6. Validation of the estimated SSC using ADCP and measured SSC using gravimetric analysis

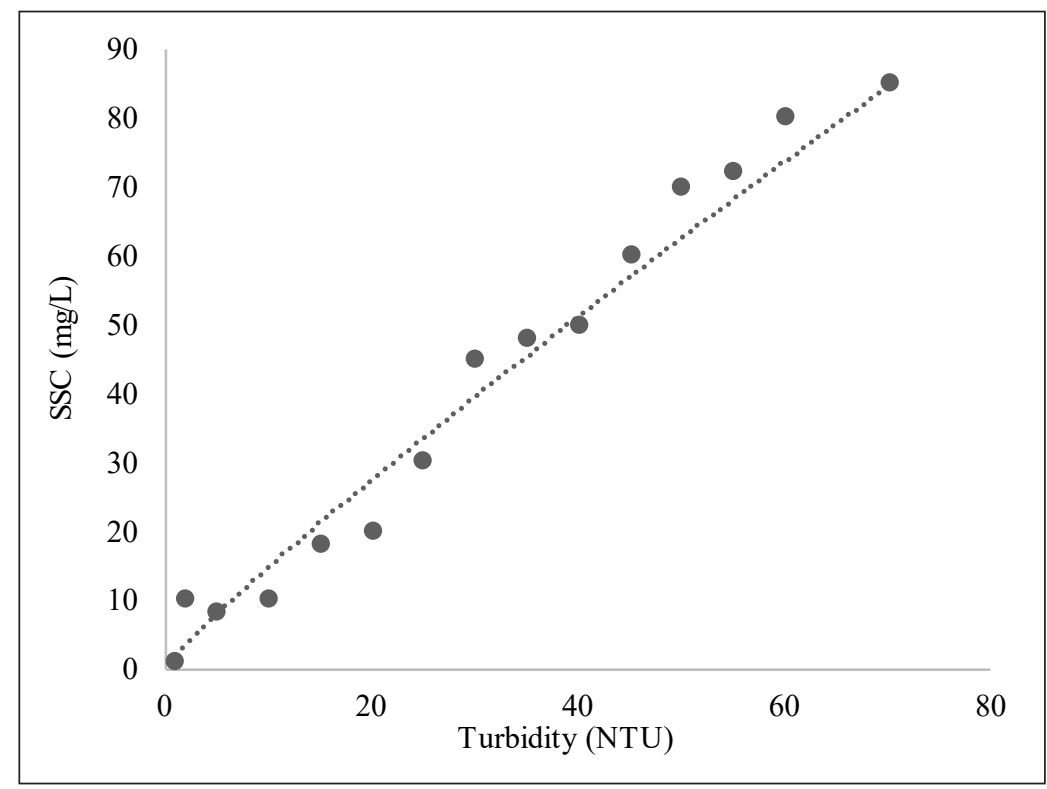

Figure 7. Suspended sediment calibration for a turbidity probe

for every 1 count. The intensity value (in count) ranged from 80 to 180 in line 1 where the high value was at the surface while the low value was near the bottom of the water. The intensity value in line 2 ranged from 60 in deep waters to 180 counts on the surface. Overall, the backscatter pattern in lines 1 and 2 had similarities, in the surface layer to a depth of $10 \mathrm{~m}$ was the layer with the highest intensity and the intensity decreased with increasing depth. 


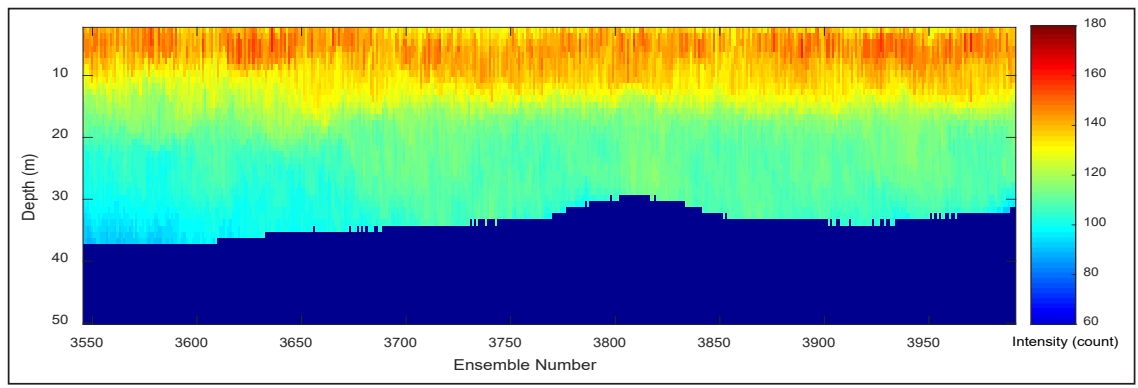

(a)

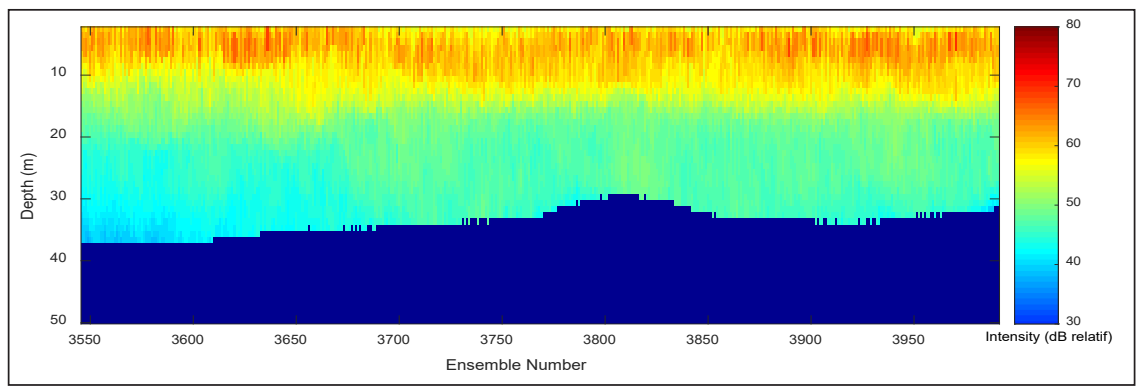

(b)

Figure 8. Example of the results of conversion of backscatter values in units of count (a) to relative dB units (b) using a scale factor of 0.43 in line 1

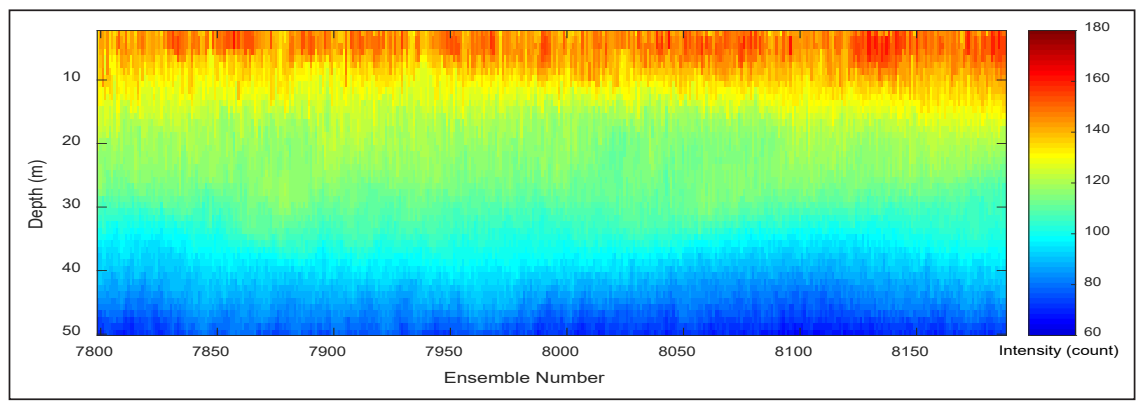

(a)

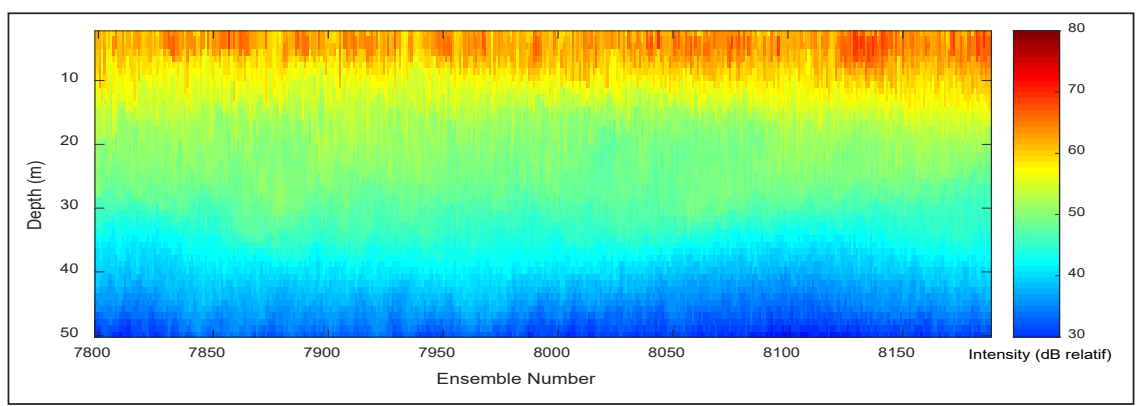

(b)

Figure 9. Example of the results of the conversion of backscatter values in units of count (a) into relative dB units (b) using a scale factor of 0.43 in line 2 
The vertical profile of SSC in lines 1 and 2 of Tidung Island waters was obtained after the backscatter value (relative $\mathrm{dB}$ ) (Figures 8 and 9) was changed to SSC (mg / L) concentration using Equation 10. The SSC concentration for each beam and the average on line 2 are presented in Figure 10 for line 1 and Figure 11 for line 2.

High SSC ( $>55 \mathrm{mg} / \mathrm{L}$ ) were in the surface layer to a depth of $12 \mathrm{~m}$. At a depth of 15 $\mathrm{m}$ to the bottom of the water the SSC ranged from $40 \mathrm{mg} / \mathrm{L}$ to $50 \mathrm{mg} / \mathrm{L}$. The area to the west (left) had a lower concentration than the east at the same depth.

In contrast to line 1, SSC on line 2 showed a variation between high, moderate, and low SSC. This is because the depth of the water on line 2 was quite deep (more than 50 $\mathrm{m}$, but because the detection distance was only set to a maximum at a depth of $50 \mathrm{~m}$, so that the bottom of the water was not detected). High concentrations (55 mg / L to $80 \mathrm{mg}$ /

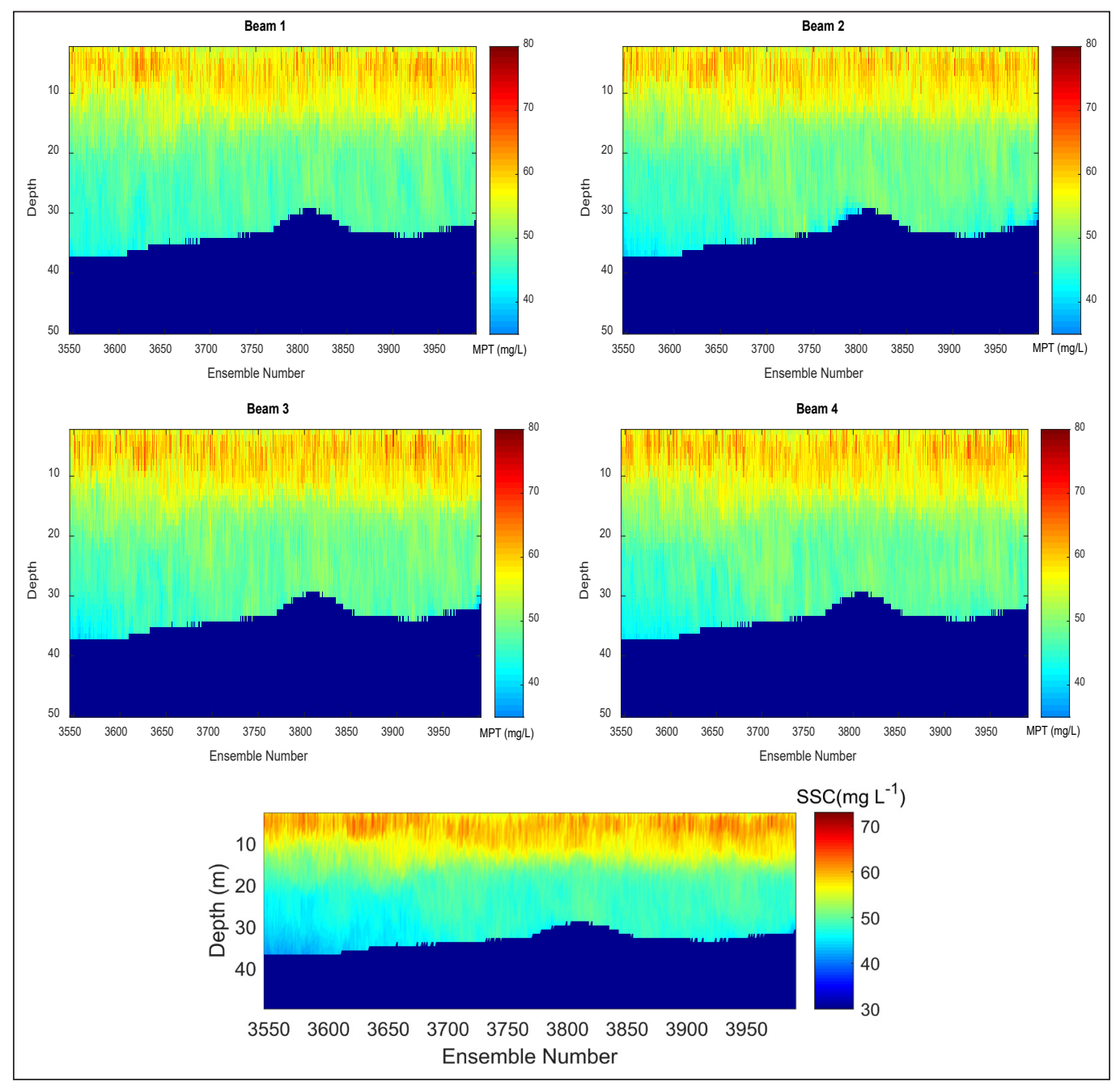

Figure 10. Distribution of SSC (mg / L) on each beam and the average in line 1. 


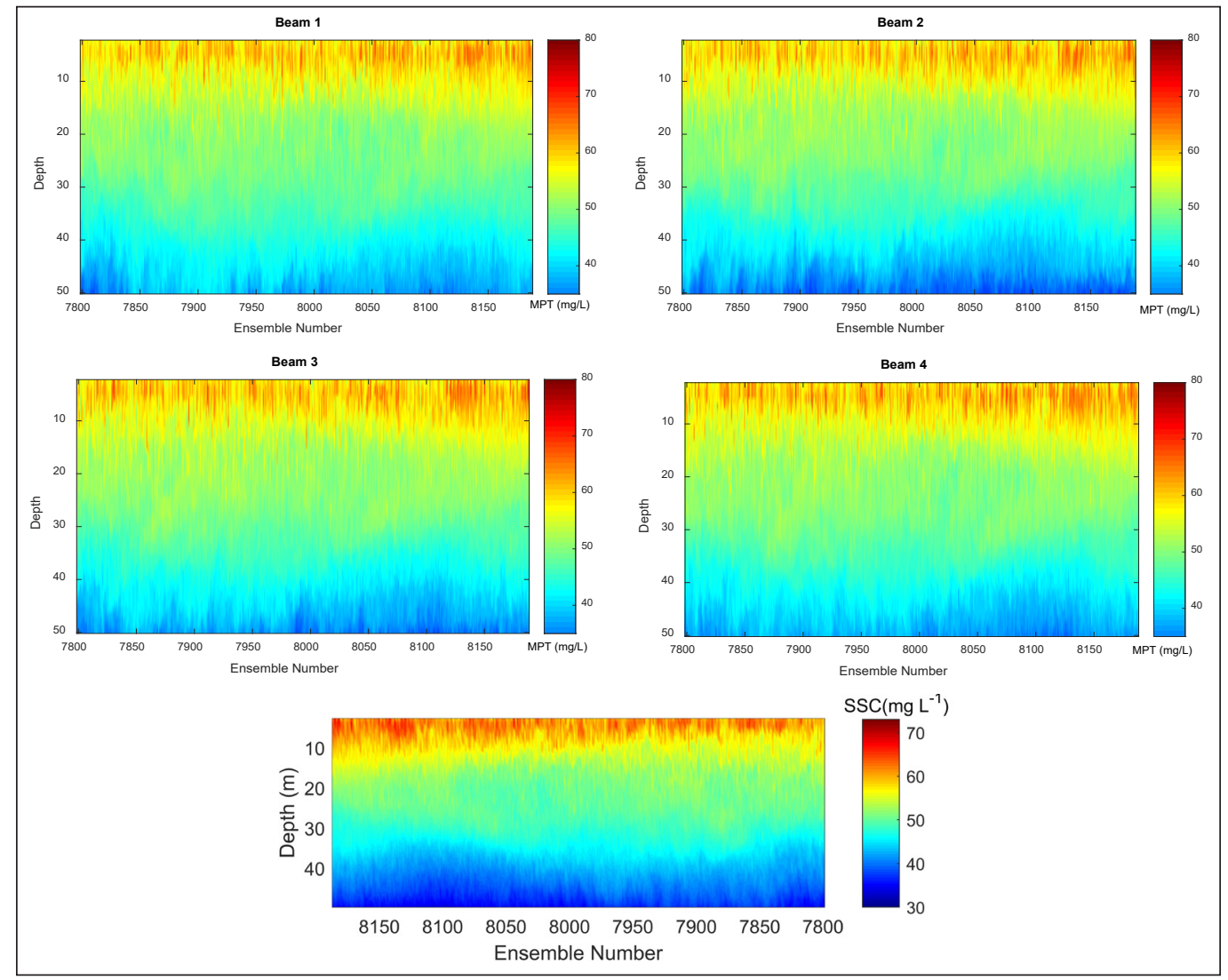

Figure 11. Distribution of SSC (mg / L) on each beam and the average in line 2

L) were found in the surface layer to a depth of $12 \mathrm{~m}$, while moderate concentrations (55 $\mathrm{mg} / \mathrm{L}$ to $45 \mathrm{mg} / \mathrm{L}$ ) were at a depth of $12 \mathrm{~m}$ to a depth of $32 \mathrm{~m}$, then low concentrations ( $<45 \mathrm{mg} / \mathrm{L}$ ) at depths greater than $40 \mathrm{~m}$. Near the sea bottom, the SSC had a wave-like contour. On the surface, the SSC in the western part was higher than the eastern part, contrasting with the SSC near the sea bottom where high concentrations were in the east. This indicates that there are different factors that affect the concentration of SSC on the surface and in deeper waters. The existence of suspended sediment in the surface bottom is coarse sediment. This is supported by the result of previous research (Li et al., 2005).

In general, the concentration of SSC on lines 1 and 2 had the same pattern where high concentrations were on the surface. This result is contrary to the results of the previous study in the Lembeh Strait which showed high concentration was located near the bottom of the water (Dwinovantyo et al., 2017). This is probably due to differences in oceanographic conditions in both waters. In addition, the concentration of SSC on line 2 (south of Tidung Island) was higher than that of line 1 (north of Tidung Island). This could be seen from the SSC of the surface layer to a depth of $10 \mathrm{~m}$. This is probably because in the southern 
part there is more have an anthropogenic activity because there are main ports and the construction of physical buildings. In addition, the southern part is also closer to Jakarta Bay which has a higher turbidity.

From this result, we had succeeded in converting echo intensity to suspended sediment concentration and validated its results with in situ measurement by using gravimetric method and turbidity sensor. By using Rayleigh scattering theory (Thorne et al., 1991), we estimated the particle size of detected suspended sediment was less than $1600 \mu \mathrm{m}$.

\section{Relationship between SSC and Ocean Current}

Extracting ADCP data resulted in the component of water current velocity and direction. The component data of the current velocity in the direction of $\mathrm{x}(\mathrm{u})$ and the velocity component in the direction $\mathrm{y}(\mathrm{v})$ are further processed to obtain the magnitude and direction of the current. The current magnitude is calculated by Equation 15 (Urick, 1996):

$$
V=\sqrt{u^{2}+v^{2}}
$$

while the direction of the north direction as $0^{\circ}$ is calculated through Equation 16:

$$
\operatorname{Direction}\left(^{\circ}\right)=270^{\circ}-a \tan ^{2}(v, u)
$$

where:

$$
\operatorname{atan} 2(v, u)=\left\{\begin{array}{lr}
\arctan \left(\frac{v}{u}\right) & \text { if } \mathrm{u}>0 \\
\arctan \left(\frac{v}{u}\right)+\pi & \text { if } \mathrm{u}<0 \text { and } \mathrm{v} \geq 0 \\
\arctan \left(\frac{v}{u}\right)-\pi & \text { if } \mathrm{u}<0 \text { and } \mathrm{v}<0 \\
+\frac{\pi}{2} & \text { if } \mathrm{u}=0 \text { and } \mathrm{v}>0 \\
-\frac{\pi}{2} & \text { if } \mathrm{u}=0 \text { and } \mathrm{v}<0 \\
\text { undefined } & \text { if } \mathrm{u}=0 \text { and } \mathrm{v}=0
\end{array}\right.
$$

with $\pi$ stand for $180^{\circ}$.

Because the current velocity and the concentration of suspended solids vary with depth, a correlation is performed for the average current data and suspended solids concentration (SSC) for all pinged data depths. The current relationship with SSC is expressed by Pearson linear correlation formulated as Equation 17: 


$$
r=\frac{\sum_{i=1}^{n}\left(X_{i}-\bar{X}\right)\left(Y_{i}-\bar{Y}\right)}{\left\{\sum_{i=1}^{n}\left(X_{i}-\bar{X}\right)^{2} \sum_{i=1}^{n}\left(Y_{i}-\bar{Y}\right)^{2}\right\}}
$$

where $\bar{X}=\sum_{i=1}^{n} \frac{X_{i}}{n}$ and $\bar{Y}=\sum_{i=1}^{n} \frac{Y_{i}}{n} ; \mathrm{n}$ is the amount of data per depth, $\mathrm{X}$ is the current speed while $Y$ is the SSC value.

A strong relationship if the value of $r$ approaches 1 or -1 , with a negative sign (-) stating the relationship between $\mathrm{X}$ and $\mathrm{Y}$ is the opposite. Correlations were also made for each individual ping on both lines.

Vertical distribution of suspended solids (SSC), velocity and direction of flow were shown in Figure 12. The current velocity on line 1 ranged between 0 and $0.9 \mathrm{~m} / \mathrm{s}$, but the dominant speed was 0.2 to $0.4 \mathrm{~m} / \mathrm{s}$ (blue to light blue). Figure 12 also shows the current velocity variation as well as SSC variation. High speed on the surface to a depth

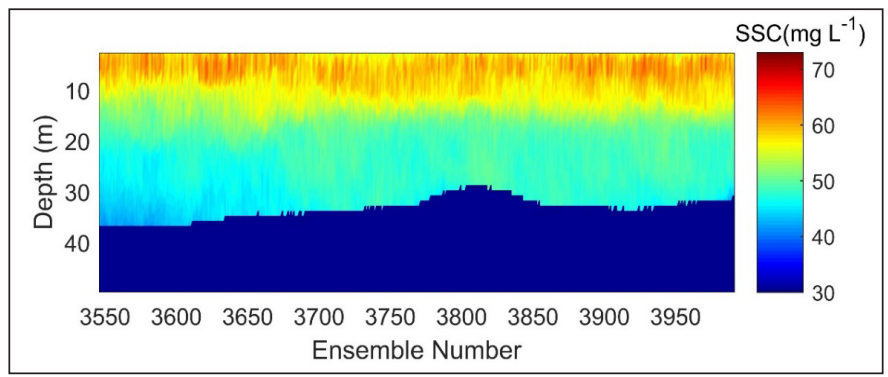

(a)

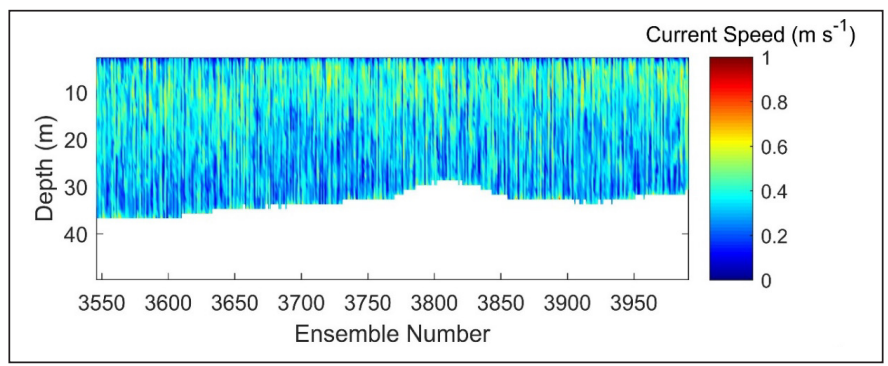

(b)

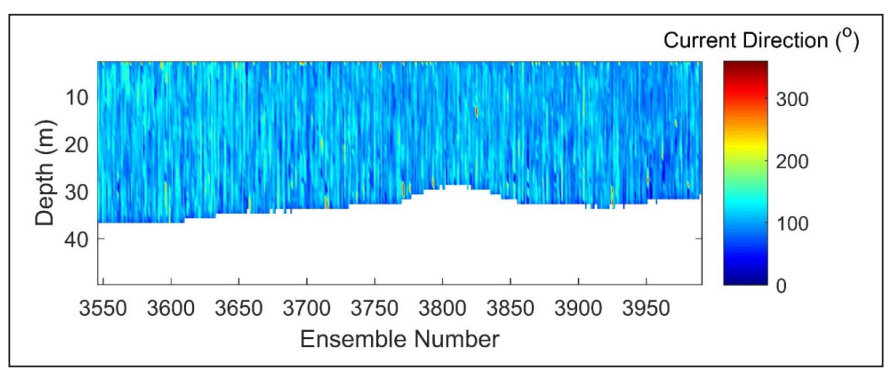

(c)

Figure 12. (a) Distribution of SSC; (b) current velocity; and (c) current direction on line 1 
of $10 \mathrm{~m}$ while low speeds were near the bottom of the water. This is because one of the driving factors was the wind so that near the surface the influence of the wind in moving sea water was very large. The direction of the flow tended to be uniform on line 1 which was towards the east. This indicates that the current driving factor on the surface to the bottom is the same. These results are in good agreement with previous research (Gartner, 2004; Park \& Lee, 2016).

The value of SSC in the eastern region had a higher value than the western region at the same depth. This is most likely caused by currents. The current direction was dominant to the east (Figure 13). This caused suspended solids to be carried eastward.

The value of current velocity on line 2 (which is in the south) was far greater than that of line 1(which was in the north). This can be seen from the red color (the value of the high current velocity, $>0.6 \mathrm{~m} / \mathrm{s}$ ) on Figure 13 on line 2 which dominates more. On line 2 there was also a stratification of the current velocity. The highest ocean current velocity

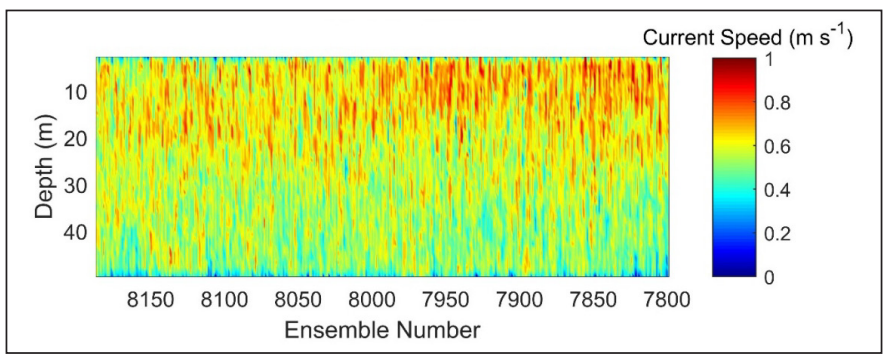

(a)

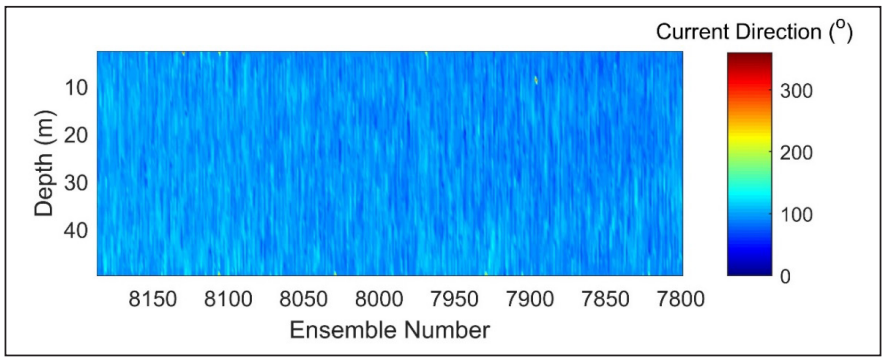

(b)

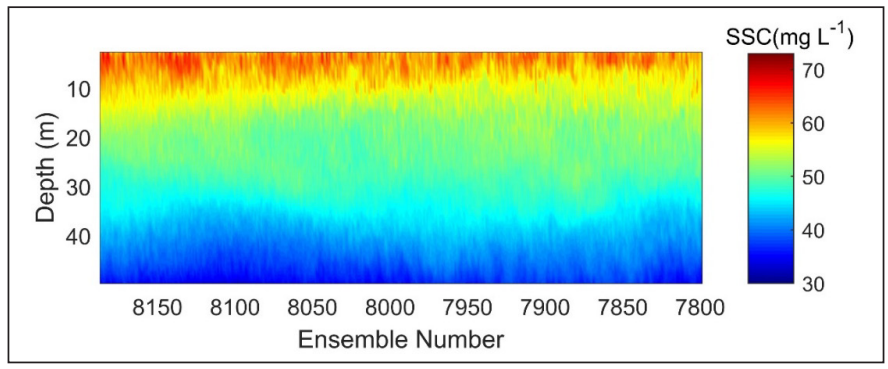

(c)

Figure 13. (a) Flow velocity distribution; (b) current direction; and (c) suspended sediment concentration 


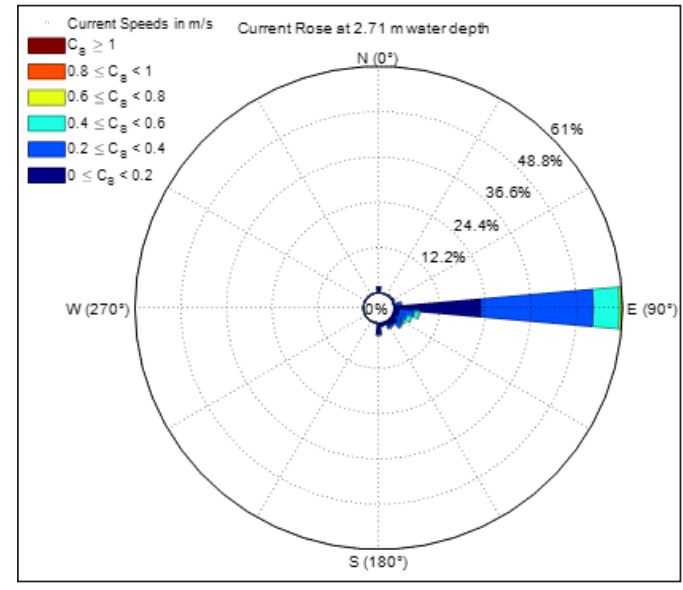

(a)

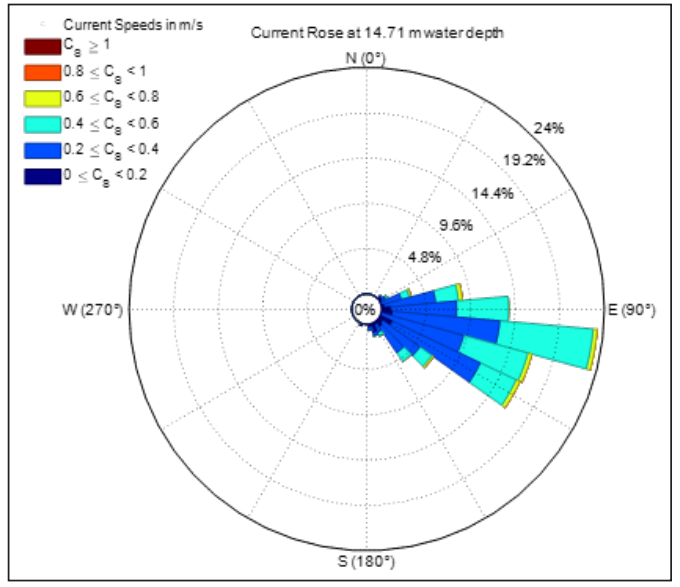

(b)

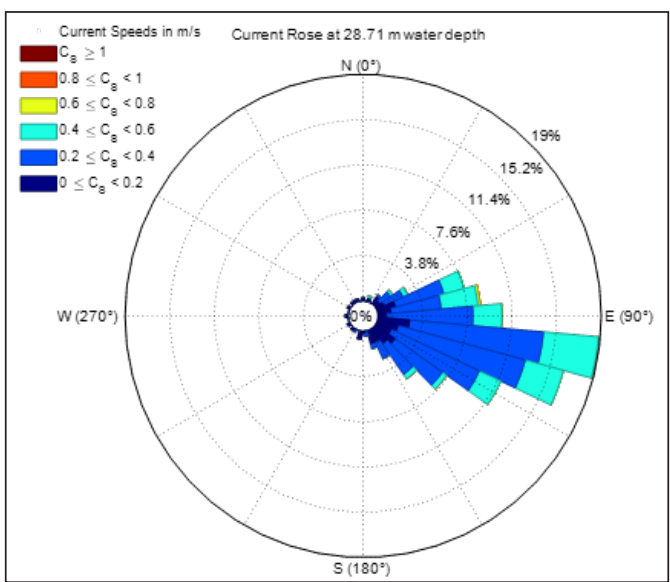

(c)

Figure 14. Current roses at: (a) $2.71 \mathrm{~m}$; (b) $14.71 \mathrm{~m}$; and (c) $28.71 \mathrm{~m}$ on line 1

value was at a depth of $10 \mathrm{~m}$, the deeper, the lower the current speed. The direction of the dominant current on line 2 was also almost the same as line 1 which was eastward.

To see more clearly how the velocity and direction of the distribution were made current rose for both trajectories in three layers of depth were $2.71 \mathrm{~m}$ depth, $14.71 \mathrm{~m}$ and $28.71 \mathrm{~m}$ each of which represented the surface conditions, the middle layer and the deeper layers (Figures 14 and 15).

At a depth of $2.71 \mathrm{~m}$, the dominant current direction went east with a speed of less than $0.6 \mathrm{~m} / \mathrm{s}$ (Figure 14). The dominant speed at this depth was 0.2 to $0.4 \mathrm{~m} / \mathrm{s}$, while the frequency of speeds of 0.4 to $0.6 \mathrm{~m} / \mathrm{s}$ was very small. At a depth of $14.71 \mathrm{~m}$, the current speed was higher than at a depth of $2.71 \mathrm{~m}$, where the speed of 0.4 to $0.6 \mathrm{~m} / \mathrm{s}$ was high, even at this depth there was a current speed of 0.6 to $0.8 \mathrm{~m} / \mathrm{s}$. The direction of flow at a depth of $14.71 \mathrm{~m}$ was more varied with the direction from east to southeast. At a depth 


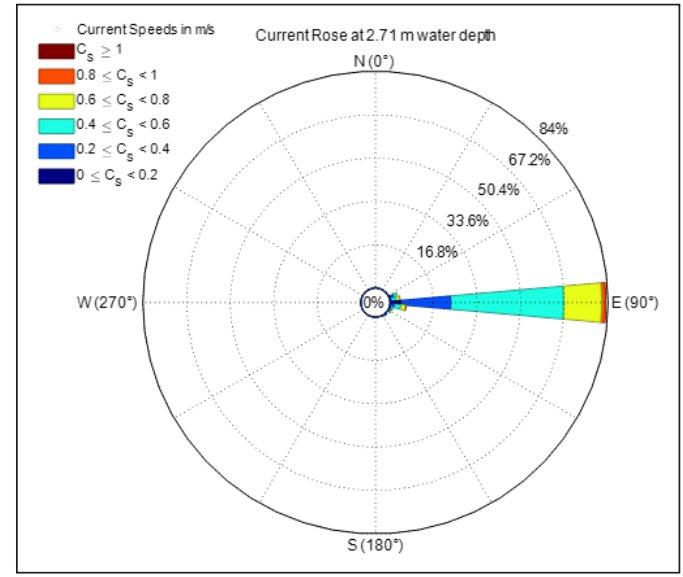

(a)

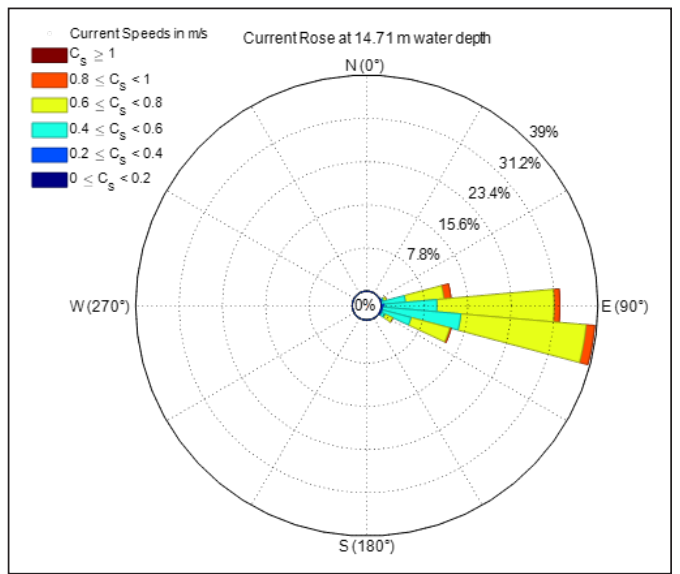

(b)

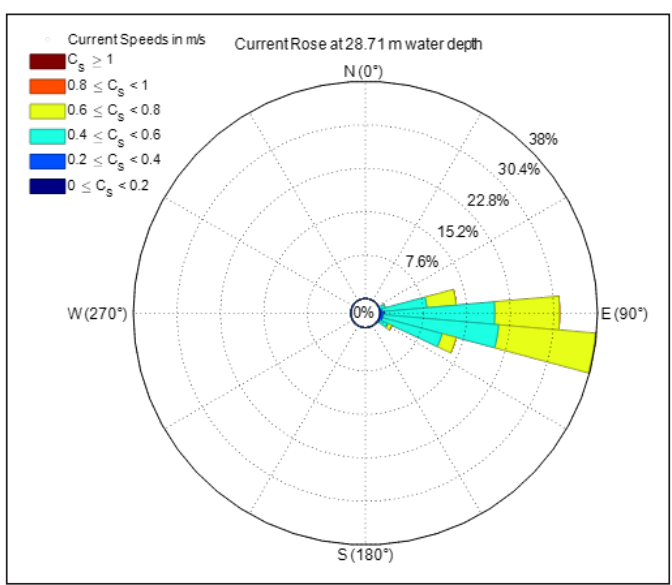

(c)

Figure 15. Current roses at: (a) $2.71 \mathrm{~m}$; (b) $14.71 \mathrm{~m}$; and (c) $28.71 \mathrm{~m}$ on line 2

of $28.71 \mathrm{~m}$, the current direction was almost the same as the depth of $14.71 \mathrm{~m}$, but the speed was lower, and was dominated at speeds of 0.4 to $0.6 \mathrm{~m} / \mathrm{s}$. This pattern is due to the surface and near the bottom, the current will have a friction which will inhibit the flow of current. The SSC distribution was influenced by tidal current and this research was in good agreement with other researchers (Li et al., 2015).

The ocean current pattern on line 2 was similar to line 1 , which was a low current velocity at a depth of $2.71 \mathrm{~m}$ and a maximum at a depth of $14.71 \mathrm{~m}$. The current velocity on line 2 was higher for each layer compared to line 1 . While the direction of the current was almost the same between line 16 and trajectory which was east to southeast (Figure 15).

The relationship between ocean current and SSC values is shown in Figure 16. This relationship is expressed by Pearson's correlation coefficient. Correlation was performed on the average data of current velocity and SSC. 


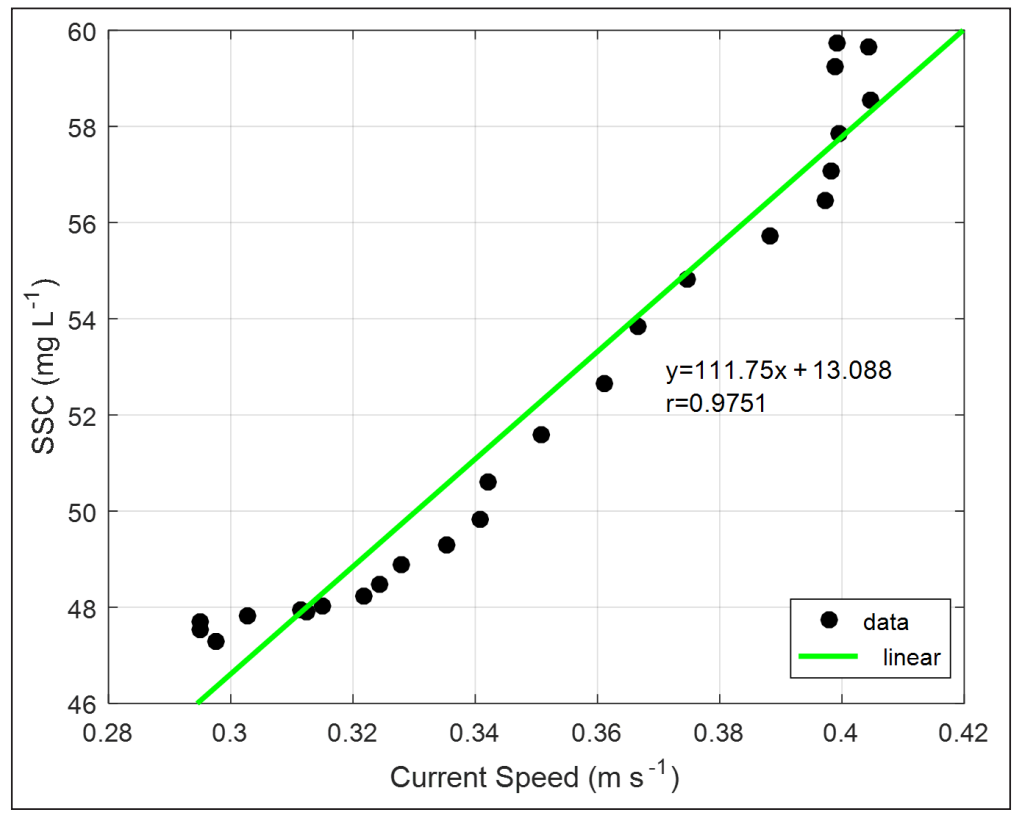

(a)

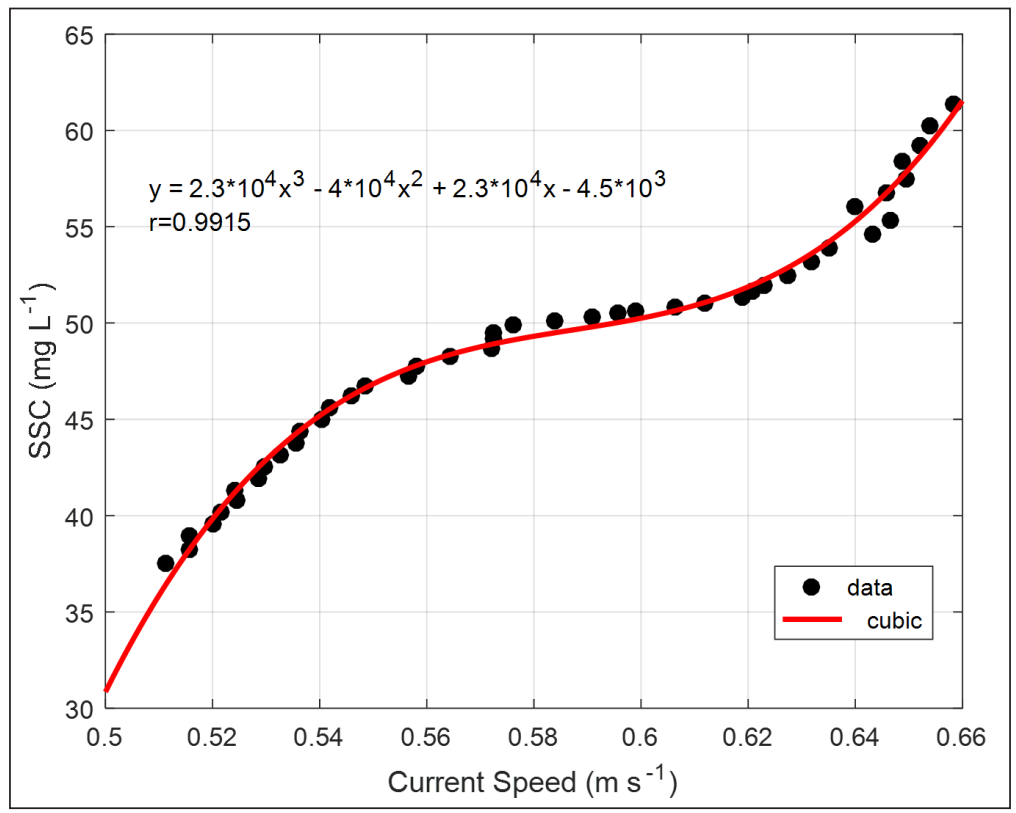

(b)

Figure 16. Relationship between current velocity with the concentration of suspended solids on: (a) line 1; and (b) line 2 
The average current velocity of each depth with the SSC value of each depth on lines 1 and 2 had a very high linear correlation of 0.97 for lines 1 (Figure 16a) and 0.99 for line 2 (Figure 16b). Based on Figure 16, the SSC value was high in a fast ocean current. This is related to the settling velocity of suspended particles which is influenced by the velocity of the fluid and the grain size of the particles. In small currents, suspended solids will settle faster so that the concentration in the water column will decrease. Conversely, if the velocity is high, suspended solids will continue to float carried by the current in the water column so that the concentration is high. This is confirmed from the vertical SSC profile and current. The effect of onshore SSC increased on the tidal pumping of sediment. This is also found by previous researchers (Wall et al., 2006; Yu et al., 2012). The highest SSC value on both lines was at a depth of 5 to $15 \mathrm{~m}$, corresponding to the maximum current velocity value at that depth. In addition, the higher SSC value on the line 2 compared to the line 1 also confirms that it corresponds to the higher current velocity on line 2 higher than the line 2. This indicates that there is a difference in the transport mechanism or the size of the dissolved particles between the two lines. This research result is in agreement to previous research (Chen et al., 2006; Jiang et al., 2007; Moore et al., 2012; Rai \& Kumar, 2015). They stated that ocean hydrodynamics and biological processes affected the distribution of suspended sediment. Sediment transport in coastal water is important because of the impact it has on water quality, turbidity, marine habitats (Tessier et al., 2008; Thorne et al., 2014). In the next research we suggest to measure the attenuation of suspended sediment for computing sonar equation to gain the SSC. We had effectively used a new technology using ADCP because it is recognized as having the capability of measuring suspended sediment with high spatial-temporal resolution and ocean current simultaneously.

\section{CONCLUSION}

Acoustic Doppler Current Profiler (ADCP) had been used to quantify the concentration of suspended sediments. The estimated SSC from the acoustic technique showed a high correlation coefficient of 0.98 with in situ measurement using gravimetric method. In general, the distribution of SSC for line 1 and line 2 for all ADCP beams had the same pattern where high SSC occurred at the sea surface.

ADCP measurements reliably assess SSC from the water column until the seabed. Sonar equation theory confirms the empirical calibration. By using Rayleigh scattering theory for $300 \mathrm{kHz}$ frequency, the particle size of suspended sediment of less than 1600 $\mu \mathrm{m}$ was predicted.

The ocean hydrodynamic condition such as ocean current is the key factor responsible for SSC distribution in the study area. 


\section{ACKNOWLEDGMENT}

The authors are grateful to Ministry of Education and Culture of Indonesia for providing research funding through Fundamental Research Scheme. The authors also thank the anonymous reviewers for their comments and suggestion to this manuscript.

\section{REFERENCES}

Ainslie, M. A., \& McColm, J. G. (1998). A simplified formula for viscous and chemical absorption in sea water. The Journal of the Acoustical Society of America, 103(3), 1671-1672. doi: https://doi.org/10.1121/1.421258

American Public Health Association. (2012). Standard methods for the examination of water and wastewater (22nd Ed.). Washington, USA: APHA.

Chen, S. L., Zhang, G. A., Yang, S. L., \& Shi, J. Z. (2006). Temporal variations of fine suspended sediment concentration in the Changjiang River estuary and adjacent coastal waters, China. Journal of Hydrology, 331(1-2), 137-145. doi: https://doi.org/10.1016/j.jhydrol.2006.05.013

Deines, K. L. (1999, March 13). Backscatter estimation using broadband acoustic Doppler current profilers. In Proceedings of the IEEE Sixth Working Conference on Current Measurement (pp. 249-253). San Diego, CA, USA. doi: 10.1109/CCM.1999.755249

Downing, J. P. (1996, February 12-13). Suspended sediment and turbidity measurements in streams: What they do and do not mean. In Automatic Water Quality Monitoring Workshop (Vol. 12, p. 13). Richmond, Canada.

Dwinovantyo, A., Manik, H. M., Prartono, T., \& Ilahude, D. (2017). Estimation of suspended sediment concentration from Acoustic Doppler Current Profiler (ADCP) instrument: A case study of Lembeh Strait, North Sulawesi. In IOP Conference Series: Earth and Environmental Science (Vol. 54, No. 1, p. 012082). Bristol, UK: IOP Publishing. doi:10.1099/1755-1315/54/1/012082.

Francois, R. E., \& Garrison, G. R. (1982a). Sound absorption based on ocean measurements: Part I: Pure water and magnesium sulfate contributions. The Journal of the Acoustical Society of America, 72(3), 896-907. doi: https://doi.org/10.1121/1.388170

Francois, R. E., \& Garrison, G. R. (1982b). Sound absorption based on ocean measurements. Part II: Boric acid contribution and equation for total absorption. The Journal of the Acoustical Society of America, 72(6), 1879-1890. doi: https://doi.org/10.1121/1.388673

Gartner, J. W., \& Cheng, R. T. (2001, March 25-29). The promises and pitfalls of estimating total suspended solids based on backscatter intensity from acoustic Doppler current profilers. In Proceedings of the Seventh Federal Interagency Sedimentation Conference (Vol. 25, pp. 119-126). Reno, Nevada.

Gartner, J. W. (2004). Estimating suspended solids concentrations from backscatter intensity measured by acoustic Doppler current profiler in San Francisco Bay, California. Marine Geology, 211(3-4), 169-187. doi: https://doi.org/10.1016/j.margeo.2004.07.001

Ghaffari, P., Azizpour, J., Noranian, M., Chegini, V., Tavakoli, V., \& Shah-Hosseini, M. (2011). Estimating suspended sediment concentrations using a broadband ADCP in Mahshahr tidal channel. Ocean Science Discussions, 8(4), 1601-1630. doi: https://doi.org/10.5194/osd-8-1601-2011 
Gruber, P., Felix, D., Storti, G., Lattuada, M., Fleckenstein, P., \& Deschwanden, F. (2016). Acoustic measuring techniques for suspended sediment. In IOP Conference Series: Earth and Environmental Science (Vol. 49, No. 12, p. 1-11). Bristol, UK: IOP Publishing. doi: https://doi.org/10.1088/1755-1315/49/12/122003

Holdaway, G. P., Thorne, P. D., Flatt, D., Jones, S. E., \& Prandle, D. (1999). Comparison between ADCP and transmissometer measurements of suspended sediment concentration. Continental Shelf Research, 19(3), 421-441. doi: https://doi.org/10.1016/S0278-4343(98)00097-1

Li, J., Li, J., Xu, J., Qiao, L., Dong, P., Ding, D., .. \& \& Sun, P. (2015). Seasonal suspended particles distribution patterns in Western South Yellow Sea based on Acoustic Doppler Current Profiler observation. Journal of Ocean University of China, 14, 385-398. doi: https://doi.org/10.1007/s11802-015-2762-2

Jiang, S., Dickey, T. D., Steinberg, D. K., \& Madin, L. P. (2007). Temporal variability of zooplankton biomass from ADCP backscatter time series data at the Bermuda Testbed Mooring site. Deep Sea Research Part I: Oceanographic Research Papers, 54(4), 608-636. doi: https://doi.org/10.1016/j.dsr.2006.12.011

Li, G. X., Yang, Z. G., \& Liu, Y. (2005). The research of the origin of the sea bottom sedimentary environment in China seas. Beijing, China: The Science Publishing Company.

Manik, H. M., Gultom, D. A., Firdaus, \& Elson, L. (2020). Evaluation of ADCP backscatter computation for quantifying suspended sediment concentration. IOP Conference Series: Earth and Environmental Science, 429, 1-7.

Medwin, H., \& Clay, C. S. (1997). Fundamentals of acoustical oceanography. Massachusetts, USA: Academic press.

Moore, S. A., Le Coz, J., Hurther, D., \& Paquier, A. (2012). On the application of horizontal ADCPs to suspended sediment transport surveys in rivers. Continental Shelf Research, 46, 50-63. doi: https://doi. org/10.1016/j.csr.2011.10.013

Park, H. B., \& Lee, G. H. (2016). Evaluation of ADCP backscatter inversion to suspended sediment concentration in estuarine environments. Ocean Science Journal, 51(1), 109-125. doi: https://doi. org/10.1007/s12601-016-0010-3

Poerbandono, R., \& Mayerle, R. (2004, October 3-7). Assesment of approaches for converting acoustic echo intensity into suspended sediment concentration. In Proceedings 3rd FIG Regional Conference (pp. 1-13). Jakarta, Indonesia.

Poerbandono, R., \& Suprijo, T. (2013). Modification of attenuation rate in range normalization of echo levels for obtaining frequency-dependent intensity data from $0.6 \mathrm{MHz}$ and $1.0 \mathrm{MHz}$ devices. Journal of Engineering and Technological Sciences, 45(2), 140-152. doi: http://dx.doi.org/10.5614\%2Fj.eng. technol.sci.2013.45.2.3

Rai, A. K., \& Kumar, A. (2015). Continuous measurement of suspended sediment concentration: Technological advancement and future outlook. Measurement, 76, 209-227. doi: https://doi.org/10.1016/j. measurement.2015.08.013

Sassi, M. G., Hoitink, A. J. F., \& Vermeulen, B. (2012). Impact of sound attenuation by suspended sediment on ADCP backscatter calibrations. Water Resources Research, 48(9), 1-14. doi: https://doi. org/10.1029/2012WR012008 
Simmonds, J., \& MacLennan, D. N. (2005). Fisheries acoustic: Theory and practice (2nd Ed.). Oxford, UK: Blackwell Science.

Tessier, C., Le Hir, P., Lurton, X., \& Castaing, P. (2008). Estimation of suspended sediment concentration from backscatter intensity of Acoustic Doppler Current Profiler. Comptes Rendus Geoscience, 340(1), 57-67.

Thorne, P. D., MacDonald, I. T., \& Vincent, C. E. (2014). Modelling acoustic scattering by suspended flocculating sediments. Continental Shelf Research, 88, 81-91. doi: https://doi.org/10.1016/j.csr.2014.07.003

Thorne, P. D., Vincent, C. E., Hardcastle, P. J., Rehman, S., \& Pearson, N. (1991). Measuring suspended sediment concentrations using acoustic backscatter devices. Marine Geology, 98(1), 7-16. doi: https:// doi.org/10.1016/0025-3227(91)90031-X

Urick, R. J. (1996). Principles of underwater sound (3rd Ed.). California, USA: Peninsula Publishing.

Wall, G. R., Nystrom, E. A., \& Litten, S. (2006). Use of an ADCP to compute suspended-sediment discharge in the tidal Hudson River, New York. Scientific Investigations Report 2006-5055. New York Water Science Center. doi: https://doi.org/10.3133/sir20065055

Yu, Q., Wang, Y. P., Flemming, B., \& Gao, S. (2012). Tide-induced suspended sediment transport: Depthaveraged concentrations and horizontal residual fluxes. Continental Shelf Research, 34, 53-63. doi: https:// doi.org/10.1016/j.csr.2011.11.015 
